\title{
Innovación educativa
}

\begin{abstract}
A sumiendo su papel como escenario para el debate y promoción de los diferentes intereses de la educación distrital, el presente número de la Revista Educación y Ciudad se dirige a una de las cuestiones de mayor importancia para la actualidad y el futuro de la profesión docente: la innovación como práctica indispensable en el contexto de una escuela que busca su consolidación como comunidad académica. Con esto en mente, se abordan iniciativas que hacen parte del quehacer diario de los docentes, especialmente desde la perspectiva de resaltar su disposición por realizar cambios que favorezcan, no solo el aprendizaje, sino el crecimiento personal de sus alumnos, elementos que, dicho sea de paso, son referentes esenciales de la visión institucional del IDEP.

En el marco de una aproximación diversa, la presente publicación dará una visión de los proyectos y perspectivas de los maestros en la ciudad, alrededor de la innovación como recurso empleado para la cualificación docente y el mejoramiento de la enseñanza, a partir de una serie de trabajos que permitirán al lector disponer de un panorama que le conecte y actualice frente a las diferentes iniciativas que buscan transformar la escuela y su funcionamiento, ya sea en las aulas, con el desarrollo del currículo, las pedagogías y la evaluación, o desde actividades extracurriculares, la gestión o el medio ambiente y la diversidad.

En principio, vale la pena rescatar el ánimo de los profesores por encontrar nuevos caminos de transformación del escenario educativo, empleando la innovación como argumento que enriquece los debates e implica la participación de diferentes disciplinas y saberes, desde perspectivas diversas. Así, el primer punto de referencia puede ser el artículo "La innovación: asunto central de la sociedad del siglo XXI. Una búsqueda educativa por modernizar-transformar la escuela", que da un panorama general de la importancia de la innovación en los procesos educativos del presente siglo, destacando su lugar en la evolución de la escuela y los elementos que intervienen en su desarrollo como fenómeno que trasciende los escenarios culturales y sociales de la actualidad.

Continuando, la innovación se constituye en materia que permite replantear el modelo vigente de educación; tal es el asunto principal del texto "Innovación disruptiva. Esperanza para la educación de futuro", que, desde un repaso por las innovaciones disruptivas, viéndolas como camino para hallar nuevas posibilidades y recursos, preguntas y relaciones, busca exponer algunas alternativas. El mismo ánimo por ver la innovación como factor decisivo es compartido por el autor de "Intrusiones cuánticas en educación”, quien considera la relación entre lo cuántico y la innovación educativa, junto a su aplicación en las TIC, como un buen punto de partida para crear un nuevo paradigma educativo; mientras que "Un nuevo paradigma educativo" expone la necesidad de replantear la sociedad del conocimiento desde la colaboración y el sentido de comunidad, para facilitar sistemas educativos que formen para la innovación y la creatividad.
\end{abstract}




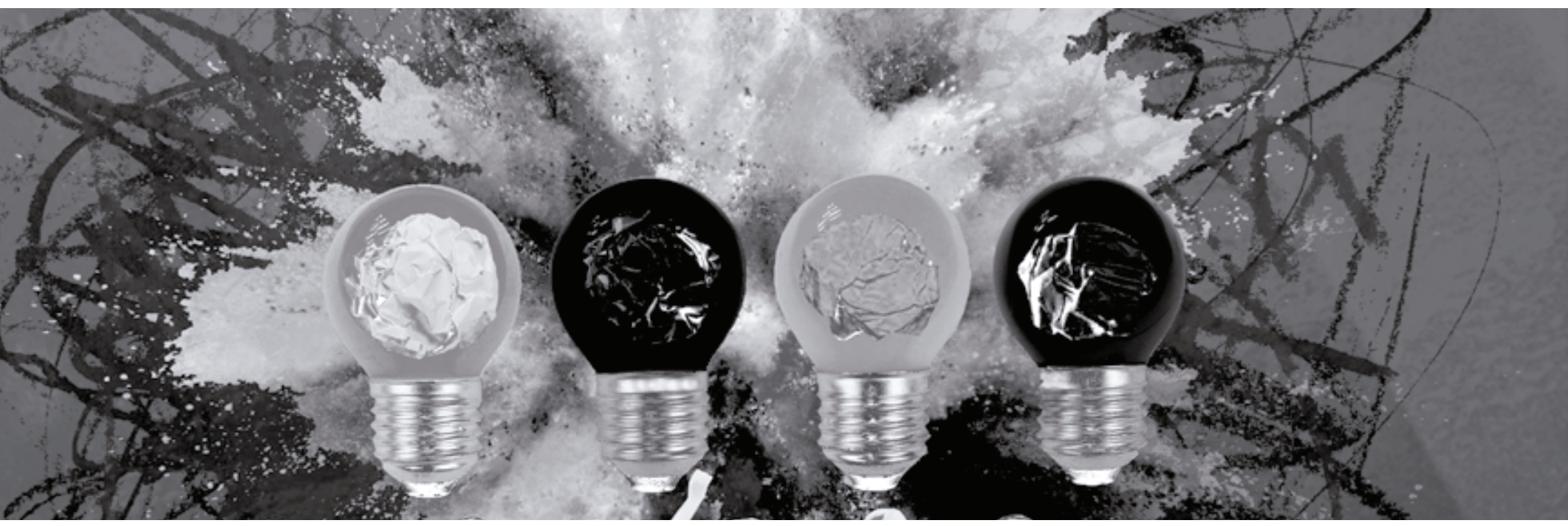

Por otra parte, la creciente importancia de la innovación en los procesos escolares ha llevado a algunos autores a analizarla desde los parámetros que inciden en la capacidad de innovar; en "El papel de la investigación en la consolidación de las innovaciones" se estudia el papel de la investigación en la consolidación y expansión de los horizontes de las innovaciones pedagógicas. Mientras tanto, el trabajo realizado en "Innovación en la ciudad educadora" presenta los resultados preliminares de un estudio de caracterización de las experiencias de innovación educativa en Bogotá, adelantado para identificar la importancia de la innovación en los escenarios educativos y las prácticas docentes de la ciudad.

Cambiando de perspectiva, la innovación es también reconocida como figura importante en las formas de resistencia desarrolladas por los maestros frente al presente de la educación; en "Innovar para una escuela otra" se exponen algunas herramientas conceptuales de Michel Foucault para emplearlas como filtro analítico de los fenómenos educativos, viendo la innovación a partir de su relevancia como vehículo de empoderamiento personal y ético. Al tiempo, en "La innovación de la práctica educativa como lugar de resistencia del maestro", se presentan elementos de reflexión sobre los procesos de innovación, a partir de una experiencia desarrollada para promover procesos de formación ético política con niños y niñas en contextos de vulneración de derechos.
Sumado a lo anterior, es necesario llamar la atención sobre el lugar de la innovación en los procesos que implican la diversidad e igualdad; este es el punto central de trabajos como "Con-Jugar con MuisKanoba. Matriz para la intervención pedagógica en el Colegio Santa Ana de Suacha”, o "Tejiendo saberes ambientales, lo ancestral, territorio y convivencia", en donde se consideran los conocimientos ancestrales como eje pedagógico que dialoga con las disciplinas la educación para proponer innovaciones en el aula. Esta perspectiva es compartida por lo referido en "Notiarrayanes: más que una práctica pedagógica, un sitio para fomentar el encuentro, el diálogo y la construcción”, experiencia que trabaja desde el acercamiento de la comunidad educativa a las TIC para promover la construcción de identidad desde el reconocimiento de lo rural; mientras que en "Mujer y matemáticas. Educación para la equidad de género y los Derechos Humanos", se recurre a una experiencia de innovación desde la perspectiva de de la educación en equidad de género como escenario pedagógico en la clase de matemáticas.

Finalmente, habría que señalar un grupo de artículos que destacan el lugar de la innovación como instrumento educativo, útil para la enseñanza particular de saberes diversos, como la lectura, el yoga o las cuestiones socio científicas; en "Propuesta innovadora para la introducción de la lectura en la escuela primaria”, se presenta un método innovador para la introducción de la lectura, basado en el paradigma histórico-cultural y la teoría de la 
actividad; mientras que "La educación como desarrollo personal", expone una propuesta de innovación educativa que, desde actividades corporales y espirituales como el yoga, la meditación o el Tai-chi, busca enriquecer el currículo escolar para atender necesidades e inquietudes desde una perspectiva no occidental; y en "Interfaz Universidad-Escuela: innovaciones pedagógicas a partir del desarrollo de un MOOC sobre Cuestiones Socio Científicas (CSC) como estrategia didáctica", se explican los resultados de una investigación que trabajó las cuestiones socio científicas como estrategia didáctica, empleando los medios digitales para fortalecer las relaciones entre la universidad y la escuela.

Como se puede ver, la innovación implica diversidad de sentidos y toca múltiples aspectos de la escuela de hoy; el trabajo que se desarrolla a partir de ella construye la escuela del mañana; por eso, desde la Revista Educación y Ciudad esperamos que la lectura del presente número no solo sea de su agrado, sino que le acerque a los cambios e iniciativas adelantados por nuestros profesores que definen el futuro de todos. 